\title{
EFEITOS DA GLOBALIZAÇÃO NO ÂMBITO TRABALHISTA
}

Recebido em: $17 / 10 / 2016$

Aceito em: 02/06/2017

\author{
Daniela Menin \\ Helder Baruffi \\ Universidade Federal da Grande Dourados (UFGD) \\ Dourados - MS - Brasil
}

\begin{abstract}
RESUMO: $\mathrm{O}$ artigo objetiva, a partir das premissas expostas por Zygmunt Bauman, em "Globalização: as consequências humanas" e "Modernidade Líquida" e dos conceitos apresentados por Ugo Mattei e Laura Nader na obra "Pilhagem, quando o Estado de Direito é ilegal", realizar uma reflexão acerca dos efeitos da globalização no âmbito trabalhista. $\mathrm{O}$ estudo, de caráter analítico, destaca que o discurso perigosista no âmbito econômico mundial, fomenta o medo e a insegurança, molas propulsoras de políticas reformistas, sob o pretexto manutenção dos empregos, mas que possuem um grave efeito colateral: a redução dos direitos trabalhistas e a redução das garantias já conquistadas. Nesta esteira, o estudo considera os efeitos do fenômeno globalização, que relativiza conceitos e direitos e torna vulnerável, o que, ao menos em tese, não poderia ser alterado: os direitos fundamentais sociais, ressaltando que a globalização confere um status de dependência. Assim, observa-se, por exemplo, que a França, que outrora foi bandeira na luta pelos direitos humanos e neste contexto, dos direitos trabalhistas, hoje inspira ao mundo a relativização de muitas garantias dos trabalhadores, ecos que se observam no Brasil. Ao final, se conclui que os direitos fundamentais sociais, autenticados pelo Estado para propiciar uma vida mais digna, exprime os limites teóricos, históricos e específicos traçados pelo constituinte e que devem ser preservados. Na contra mão dessa natureza de fundamentabilidade, estão a relativização de direitos, efeitos da globalização, risco e iminente perigo, uma vez que se prestam a alterar, ainda que de forma sorrateira e camuflada os direitos fundamentais, restringindo direitos historicamente conquistados. $\mathrm{O}$ direito do trabalho não está imune a tais efeitos, vejam-se as propostas de supressão/redução de direitos atualmente em discussão, sempre em nome da modernidade e manutenção do emprego.
\end{abstract}

PALAVRAS CHAVE: Trabalho. Fatores Socioeconômicos. Trabalhadores.

\section{EFFECTS OF GLOBALIZATION IN LABOR SCOPE}

ABSTRACT: The article aims, from the premises exposed by Zygmunt Bauman in "Globalization: The human consequences" and "Modernity Liquid" and the concepts presented by Ugo Mattei and Laura Nader in the book "Plunder, when the rule of law is illegal" carry out a reflection on the effects of globalization in the workplace. The study, analytical character, points out that the perigosista discourse in the global economic context, encourages fear and insecurity, thrusts reformist policies under the guise 
maintaining jobs, but have a serious side effect: the reduction of labor rights and the reduction of guarantees already achieved. On this track, the study considers the effects of the globalization phenomenon, which relativize concepts and rights and makes it vulnerable, which, at least in theory, could not be changed: the fundamental social rights, noting that globalization gives a dependency status. Thus, it is observed, for example, that France, which was once flag in the fight for human rights and in this context, labor rights, today inspires the world to relativize many guarantees for workers, echoes that are observed in Brazil. Finally, it is concluded that the fundamental social rights, certified by the state to provide a more dignified life, expresses the theoretical, historical and specific limits set by the constituent and must be preserved. In this hand against fundamentabilidade nature, they are the relativization of rights, globalization effects, risk and imminent danger, since they lend themselves to change, albeit sneaky and covert form fundamental rights, restricting rights historically achieved. The labor law is not immune to such effects, look up the proposed elimination / reduction of tariffs currently under discussion, always in the name of modernity and maintaining employment

KEYWORDS: Work. Socioeconomic Factors. Workers.

\section{Introdução}

Em tempos de economia globalizada, pertinente a afirmação de Habermas (2012, p. 10) “A injustiça social paga-se, não com dólares, libras ou euros, mas com a 'moeda forte da existência quotidiana", afirmativa que se aplica em maior conta aos países subdesenvolvidos, dotados de uma "[...] injustiça social que brada aos céus, e que consiste no facto de os custos socializados do falhanço do sistema atingir com maior dureza os grupos sociais mais vulneráveis" (HABERMAS, 2012, p. 10).

Na mesma esteira, ressalta Bauman (2011, p. 9), que “[...] uma ponte não cai quando a carga excede as forças de sua estrutura; a ponte colapsa muito antes, quando o peso da carga supera a capacidade de suportar de um de seus pontos: o mais fraco." (em tradução livre). O mais fraco é o trabalhador, o assalariado, que, no mundo globalizado, vê reduzirem-se os postos de trabalho e seus direitos sociais duramente assegurados. A crise econômico-político-social a que nos defrontamos diariamente resulta do "[...] 
programa de submissão desenfreada do mundo da vida aos imperativos do mercado" (HABERMAS, 2012, p. 10).

Uma grande barreira a ser transposta para a preservação, evolução e efetividade dos direitos humanos, são os inúmeros efeitos do fenômeno chamado globalização, que relativiza conceitos e direitos e torna vulnerável, o que, ao menos em tese, não poderia ser alterado: os direitos fundamentais sociais. Bauman (1999) afirma que vivemos em uma modernidade líquida, onde nada realmente é feito para durar, e coisa alguma é, de fato, sólido, imutável e intangível. Nem mesmo as barreira físicas são intransponíveis e nada mais se decide de forma localizada, mas sim de maneira global. Assim, a globalização estende seus efeitos em diversas áreas, entre elas, na política, estruturas sociais, percepções do tempo e espaço e inclusive nas relações laborais.

Por conta disso, o discurso perigosista no âmbito econômico mundial, fomenta o medo e a insegurança, molas propulsoras para promover políticas e ações, sob o pretexto de viabilizar o funcionamento das empresas, mas que possuem um grave efeito colateral: a redução dos direitos trabalhistas, com a consequente redução das garantias já conquistadas para a classe obreira.

Também nota-se que a globalização confere um status de dependência de países menos desenvolvidos aos mais desenvolvidos. Assim, observa-se que a França, país que outrora serviu de exemplo na luta pelos direitos humanos e neste contexto, dos direitos trabalhistas, hoje inspira ao mundo à relativização de muitas garantias dos trabalhadores, inclusive no Brasil e que apresentam ameaças ao trabalhador. ${ }^{1}$

\footnotetext{
1 “O que se está buscando é para piorar a condição do trabalhador, se busca que os sindicatos possam abrir mão de direitos trabalhistas, permitir jornada de trabalho de 12 horas sem intervalo para refeição. Não precisa ser nenhum técnico para prever que os riscos de acidentes de trabalho adoecimento vão ser enormes, as consequências serão extremamente nefastas" destaca o Procurador Federal Ronaldo Fleury (2016), em entrevista à TV Anhanguera TO, no dia 15/09/2016.
} 
Assim, busca-se, neste estudo, delinear alguns efeitos da Globalização, conforme conceito apresentado por Zygmunt Baumam, em suas obras "Globalização: as consequências humanas" (1999) e "Modernidade Líquida" (2013) e os conceitos de pilhagem apresentados por Laura Nader e Ugo Mattei na obra "Pilhagem, quando o Estado de Direito é ilegal" (2013). Tendo por problema central os impactos da globalização nas relações trabalhistas, busca-se, neste estudo, extrair os conceitos e delinear os efeitos da globalização sob a ótica dos referidos autores, e situá-los no âmbito das relações laborais, uma vez que o Direito do Trabalho está no rol dos direitos sociais fundamentais e evidenciar as principais consequências para o trabalhador, tendo em vista a possibilidade de aprovação de alterações na legislação trabalhista no Brasil.

O estudo, de caráter analítico, busca extrair dos autores citados o fundamento para a análise dos reflexos da globalização nas relações trabalhistas e aborda, em um primeiro momento o fenômeno globalização, seus aspectos e efeitos no âmbito trabalhista e, num segundo momento, centra-se, especificamente, sobre um dos elementos que certamente mais serão atacados - a supressão do direito ao lazer, particularmente pela extensão da jornada de trabalho, proposta em discussão na reforma trabalhista no Brasil.

\section{Alguns Aspectos e Efeitos da Globalização no Âmbito Trabalhista}

O fenômeno da globalização possui alguns aspectos marcantes que interferem na promoção e conservação dos Direitos Humanos, mais especificamente no que se refere aos direitos trabalhistas. Uma dessas características é a relativização de valores e de princípios (BAUMAN, 1999), onde tudo tem natureza fluída, inconsistente e transitória. Ao mesmo tempo em que promove a internacionalização do sistema capitalista, a 
promoção da expansão industrial, crescimento da economia internacional e a geração de empregos, a globalização também provoca por parte das empresas, a busca pelo barateamento da mão de obra operária, como forma de competitividade no mercado.

É neste aspecto, que Zygmunt Bauman, em suas obras "Globalização: as consequências humanas" (1999) e "Modernidade Líquida" (2013) elucida de que maneira os efeitos da globalização podem ser percebidos de uma forma geral, inclusive no âmbito do trabalho. Para o sociólogo, o conflito existente entre funcionários e investidores é latente, principalmente no que diz respeito à forma como se desenvolve a relação com o espaço físico e com a comunidade.

Os investidores, donos das empresas, tomam as decisões importantes não estando presos à localidade, visam o lucro e a expansão de sua atividade econômica. Investidores, empresários e empregadores não se vinculam nem ao local nem às pessoas do local. Não estão presos aos limites físicos nem a qualquer tipo de laço. Nada os prendem, os limitam. A localidade escolhida para a implantação do estabelecimento para fins econômicos se presta exclusivamente para servir à intenção extrativista. Ou seja, o interesse é usufruir daquilo que a localidade oferece, sua posição geográfica, riquezas naturais e mão de obra, sem oferecer quase nada em troca.

Na outra ponta estão os empregados, geralmente aqueles que são os moradores da localidade, que não possuem voz neste processo, e estão presos ao espaço do trabalho, cabendo-lhes unicamente aceitar as condições impostas, na hipótese de desejarem o emprego oferecido.

Além de não respeitar os limites geográficos, a globalização também promove a dependência entre os países, principalmente daqueles menos desenvolvidos econômica e socialmente. Assim, a perda da autonomia na tomada de decisões nas áreas sociais e 
econômicas está vinculada aos interesses dos países mais poderosos, centrais, que ditam as regras e condutas, “[...] estruturas hegemônicas de poder” (GUIMARÃES, 1998), em detrimento dos interesses dos países periféricos, das localidades.

Em sua obra “Razões Jurídicas do Pacifismo”, Luigi Ferrajoli (2011, p.49) reflete sobre os efeitos da globalização e os possíveis rumos a serem tomados pela democracia, citando como exemplo da referida dependência dos países, a forma como Estados Unidos submetem os países menos desenvolvidos aos seus interesses.

$\mathrm{Na}$ era da globalização, com efeito, o destino de qualquer país, com a única exceção dos estados Unidos, depende cada vez menos das decisões internas adaptadas por seus governantes, principalmente se trata de países pobres, e cada vez mais de decisões externas, adotadas em rede ou por poderes políticos ou econômicos de caráter supra ou extraestatal.

Ora, tal reflexão deixa evidente um princípio básico imposto pela globalização: os atos governamentais trazem em seu bojo a intenção de proteger aqueles que detêm o poder econômico. Assim, nenhuma decisão é local, mas seu efeito já vem imbuído da missão de repercutir e respaldar os interesses dos países mais desenvolvidos.

O cenário internacional, com que se defrontam qualquer sociedade, Estado e governo, organiza-se em torno de estruturas hegemônicas de Poder, político e econômico. Essas estruturas, resultado de um processo histórico, beneficiam os países que as integram e têm como principal objetivo sua própria perpetuação (GUIMARÃES, 1998, p. 112).

Outro efeito da globalização é a necessidade de consumir, e, dessa forma, participar desse universo de maior desenvolvimento. Não que a figura do consumidor seja recente, mas é cada vez mais acentuada e promovida, inclusive nos países menos desenvolvidos. Desempenhar tal papel é fazer parte da comunidade globalizada, tratada como se fosse quase uma exigência. E para consumir, é preciso ao menos, uma fonte de renda. Bauman então argumenta que de produtora, a sociedade moderna passou a ser consumidora e que fugir do consumismo é uma tarefa praticamente impossível, uma vez 
que diz respeito à identidade dos indivíduos, sua inserção no mundo moderno e sua própria existência.

O consumidor em uma sociedade de consumo é uma criatura acentuadamente diferente dos consumidores de quaisquer outras sociedades até aqui. Se os nossos ancestrais filósofos, poetas e pregadores morais refletiram se o homem trabalha para viver ou vive para trabalhar, o dilema sobre o qual mais se cogita hoje em dia é se é necessário consumir para viver ou se o homem vive para poder consumir. Isto é, se ainda somos capazes e sentimos a necessidade de distinguir aquele que vive daquele que consome. $(1999$, p. 88$)$

No mundo globalizado, existe a falsa impressão de que a pessoa não-globalizada está fazendo uma escolha; na verdade ela foi contaminada com a necessidade de consumir para se incluir. "Todo mundo pode ser lançado na moda do consumo; todo mundo pode desejar ser um consumidor e aproveitar as oportunidades que esse modo de vida oferece. Mas nem todo mundo pode ser um consumidor" (BAUMAN, 1999, p. 94).

Ainda que não haja a liberdade e a possibilidade de se escolher o estilo de vida, consumir ainda é uma opção possível e viável. Para isso, o trabalho, ainda que em condições precárias, proporciona ao menos a expectativa de manter-se consumidor e inserido globalmente.

Assim, é possível observar que promover o consumir e relativizar as barreiras é também uma forma de manter a hegemonia dos países ricos, que estão no topo da pirâmide do processo de globalização. Dessa forma é possível observar o desenvolvimento de métodos para a implantação do processo de pilhagem nos países menos desenvolvidos (MATTEI; NADER, 2013). Observa-se, portanto, que uma de suas características é a propagação do medo e a insegurança como mecanismos de obtenção de alguma vantagem econômica. Gera-se o medo para que aqueles que estão no polo hipossuficiente da relação sejam compelidos a aceitar as condições dos que detém o poder. 
Convém elucidar que o processo de pilhagem no âmbito trabalhista pode apresentar, a princípio, uma aparência benéfica. Empresas, na maioria das vezes multinacionais, se instalam em determinadas localidades (geralmente cidades de pequeno e médio porte, mas sempre estrategicamente localizadas), muitas vezes com incentivos e benefícios fiscais, com o objetivo de impulsionar a economia local e gerar empregos. Chegam a transformar a realidade dos moradores da localidade na qual foram inseridas, gerando benefícios como pavimentação asfáltica, implantação de linhas de transporte público, além da própria geração de empregos. Por muitas vezes, até inauguram novas comunidades, mas não necessariamente tem compromisso com elas. $\mathrm{O}$ que está em prática é uma conduta extrativista, que absorve não somente as riquezas locais, mas também a força de trabalho local. O que se apresenta como uma ação de promoção e aprimoramento é, na realidade, ações orquestradas para viabilizar ainda mais sua atividade econômica, com o objetivo de sua perpetuação.

Para consumir e, assim, continuar fazendo parte de um mundo globalizado, é preciso uma fonte de renda. Mas essa fonte de renda, a saber, o emprego, pode ser comprometido pela crise financeira global, fortemente anunciada e associada ao desemprego. Neste momento entra em cena outra estratégia da globalização que também caracteriza a pilhagem, que é a disseminação do medo. Medo da perda do emprego, medo de fazer parte do exército de reserva de mercado, medo de não poder mais ser consumidor. Este medo é disseminado pela divulgação em massa pelos meios de comunicação dos índices de desemprego mundial e nacional.

Assim colocado, o problema do desemprego apresenta-se como um fenômeno global que parecer estar tomando contornos maiores a cada ano. Ainda em janeiro de 
2015, a Organização Internacional do Trabalho (OIT) fez uma projeção ${ }^{2}$ de que os índices de desemprego continuariam crescendo nos próximos anos, considerando o crescimento da economia global de uma forma mais lenta, e também continuariam crescendo o "[...] aumento das desigualdades e conflitividade social". Neste quadro, as expectativas são desalentadoras. Projeções da OIT apresentadas no informe "Perspectivas sociais e de emprego no mundo"3 são de que em 2019, mais de 212 milhões de pessoas não terão trabalho. Menos pessoas trabalhando, menos consumidores, menos crescimento global, maiores as desigualdades sociais e instabilidade político-social.

No que diz respeito ao Brasil, o país atingiu o maior índice de desemprego, segundo a pesquisa do Instituto Brasileiro de Estatística e Geografia (IBGE) iniciada em $2012^{4}$. O estudo ${ }^{5}$ apontou que a taxa de desocupação foi estimada em 11,6\% no trimestre encerrado em julho de 2016 , ficando 0,4 ponto percentual acima da observada

\footnotetext{
${ }^{2}$ http://www.ilo.org/global/about-the-ilo/newsroom/news/WCMS_336917/lang--es/index.htm

${ }^{3}$ Fonte: $\quad$ http://www.ilo.org/global/about-the-ilo/multimedia/maps-and-charts/WCMS 336950/lang-es/index.htm . Acesso em: 06 set. 2016.

${ }^{4}$ https://saladeimprensa.ibge.gov.br/noticias.html? view=noticia\&id=1\&idnoticia=3243\&busca=1\&t=pnad -continua-taxa-desocupacao-11-6-trimestre-encerrado-julho-2016. Acesso em: 06 set. 2016.

${ }_{5}^{5}$ Destina-se a produzir informações contínuas sobre a inserção da população no mercado de trabalho associada a características demográficas e de educação, e, também, para o estudo do desenvolvimento socioeconômico do País, agregando a produção de resultados anuais sobre temas permanentes da pesquisa (como trabalho infantil e outras formas de trabalho, migração, fecundidade etc.) e outros aspectos relevantes selecionados de acordo com as necessidades de informação. A pesquisa é realizada por meio de uma amostra de domicílios, extraída de uma amostra mestra, de forma a garantir a representatividade dos resultados para os diversos níveis geográficos definidos para sua divulgação. A cada trimestre, são investigados 211.344 domicílios particulares permanentes, em aproximadamente 16.000 setores censitários, distribuídos em cerca de 3.500 municípios. A periodicidade é mensal, para um conjunto restrito de indicadores relacionados à força de trabalho e somente para o nível geográfico de Brasil; trimestral, para indicadores relacionados à força de trabalho; anual, para os demais temas permanentes da pesquisa e indicadores complementares relacionados à força de trabalho; e variável, para outros temas ou tópicos dos temas permanentes a serem pesquisados com maior periodicidade ou ocasionalmente. Já a abrangência geográfica compreende as Grandes Regiões, Unidades da Federação, 20 Regiões Metropolitanas que contêm Municípios das Capitais (Manaus, Belém, Macapá, São Luís, Fortaleza, Natal, João Pessoa, Recife, Maceió, Aracaju, Salvador, Belo Horizonte, Vitória, Rio de Janeiro, São Paulo, Curitiba, Florianópolis, Porto Alegre, Vale do Rio Cuiabá, e Goiânia), Municípios das Capitais e Região Integrada de Desenvolvimento da Grande Teresina. Fonte: https://www.ibge.gov.br/home/estatistica/indicadores/trabalhoerendimento/pnad_continua_mensal/default .shtm . Acesso em: 06 set. 2016.
} 
no trimestre móvel que vai de fevereiro a abril (11,2\%), também de 2016 . Se forem comparados os números com o mesmo trimestre do ano anterior, quando a taxa foi estimada em 8,6\%, também ocorreu elevação, no caso, de 3,0 pontos percentuais. Além disso, a população desocupada, que atualmente é de 11,8 milhões de pessoas, cresceu 3,8\% na comparação com o trimestre fevereiro-abril (11,4 milhões), ou seja, um acréscimo de 436 mil pessoas. No confronto com igual trimestre do ano passado, esta estimativa subiu $37,4 \%$, o que representa um aumento de 3,2 milhões de pessoas.

Além disso, também compõe os dados da referida pesquisa, a informação de que, apesar do número de empregados com carteira assinada (34,3 milhões) não ter apresentado variação estatisticamente significativa em comparação com trimestre de fevereiro a abril de 2016, se comparado ao trimestre de maio a julho de 2015 , houve queda de 3,9\%, uma perda de 1,4 milhão de pessoas com carteira assinada.

Também se observa que o rendimento médio real habitualmente recebido em todos os trabalhos é de $\mathrm{R} \$ 1.985,00$ (mil novecentos e oitenta e cinco reais), com declínio de 3,0\% em relação ao mesmo trimestre do ano anterior de 2015 , que era de $\mathrm{R} \$$ $2.048,00$ (dois mil reais e quarenta e oito centavos).

Tais números refletem a desaceleração na economia brasileira que refletiu no mercado de trabalho e também no rendimento mensal do trabalhador. O medo de engrossar as estatísticas de desempregados atinge desde o mais alto escalão das empresas até os cargos com salários mais baixos. Valendo-se do período de instabilidade econômica e do aumento do desemprego, as empresas propõem a redução de benefícios e o aumento de responsabilidades para os empregados.

No mundo globalizado, o medo apresenta-se como uma estratégia e como elemento que preenche lacunas e gera um sentimento de satisfação e gratidão pelo 
pouco. Em outras palavras, os direitos são flexionados sob o pretexto de manter os postos de serviço e de barrar o aumento das estatísticas, e aqueles que mantém os empregos sentem-se privilegiados, mesmo com perdas significativas no poder de compra, frente ao número cada vez maior de desempregados.

Assim, os números promovem o medo, que geram ainda mais insegurança no dia a dia do trabalhador e até mesmo em sua vida pessoal. A todo custo, procura-se manter aquilo que se presta, na maioria das vezes, apenas para prover a subsistência, mas não a vida digna, firmada em sólidos alicerces.

Aliás, para o trabalhador já não há mais certezas. Neste contexto, quando fala a respeito dos laços humanos num mundo fluído, mencionando que os valores morais estão cada vez mais subjugados e invertidos, Bauman (2013, p.200) refere-se também à precariedade, a instabilidade, vulnerabilidade das certezas da vida moderna, em seus mais diversos aspectos.

Os teóricos franceses falam de précarité, os alemães, de Unsicherheit e Risikogeselschaft, os italianos, de incerteza e os ingleses de isecurty - mas todos tem em mente o mesmo aspecto da condição humana, experimentada de várias formas e sob nomes diferentes por todo o globo, mas sentida como especialmente enervante e deprimente na parte altamente desenvolvida e próspera do planeta-por ser um fato novo sem precedentes. $\mathrm{O}$ fenômeno que todos esses conceitos tentam captar e articular é a experiência combinada de falta de garantias( de posição, títulos e sobrevivência), da incerteza (em relação À sua continuação e estabilidade futura) $e$ de insegurança (do corpo, do eu e de suas extensões:posse, vizinhanças e comunidade).

Assim, o homem globalizado, o cidadão comum, o trabalhador, vive relações precárias e frágeis, e convive dia após dia com a instabilidade, incerteza e o medo de que tudo que aparentemente possui, possa se desfazer, inclusive no que diz respeito ao trabalho e emprego, meio pelo qual ele tenta sua sobrevivência. Dessa forma, observa- 
se que a insegurança estabelece uma linha tênue entre a conservação do emprego e a aceitação de condições precárias de trabalho.

Neste quadro de fragilidade econômico-social, diante da necessidade de permanecer inserido no mundo globalizado e do medo de da perda do pouco que lhe é oferecido, apresenta-se o terreno fértil e propício para a manifestação da fluidez e da modernidade líquida, assinalada por Bauman (2013): a flexibilização dos direitos trabalhistas.

Outra faceta da flexibilização manifesta-se nesse cenário de incertezas e de vulnerabilidade, e apresenta-se reforçada por outro mecanismo bastante comum, inclusive no âmbito trabalhista, a saber, a barganha. Ugo Mattei e Laura Nader, em sua obra "Pilhagem: Quando o Estado de Direito é ilegal" (2013, p.23) explicam que, uma das formas adotadas para implantar a cultura ocidental nos países orientais, é a disseminação por prestígio, o uso da força e a barganha. Esta última, representa a imposição aos países alvos de estruturas jurídicas ocidentais, para que os orientais não sejam expulsos dos mercados mundiais. Ou seja, reveste-se de legalidade, mas na verdade é uma "sutil extorsão". Dessa forma, o poder é exercido de forma vertical, onde o mais forte dita as regras, lícitas e legais, diga-se de passagem, mas extremamente vantajosas apenas para a parte mais forte da relação.

$\mathrm{Na}$ prática das relações laborais, ainda que o trabalhador identifique que a sobrevivência econômica da empresa está sendo promovida à custa do respeito às suas garantias mínimas e indispensáveis à sua dignidade humana, ele se vê compelido a aceitar. Ou aceita, ou perde o pouco que tem. Assim o faz, pois de forma alguma deseja perder o emprego, o status de indivíduo produtivo e de membro inserido no mundo consumidor globalizado. 
De certa forma, uma história relatada por Bauman (2013, p.181) reflete de uma só vez algumas das principais características da globalização, como o medo e a barganha. Cita Bauman que Henry Ford, que, a princípio declarava não dar importância para a manutenção de empregados em sua indústria de veículos, uma vez que, segundo ele, o mais importante era a linha de produção não estar parada, não importado por quem fosse impulsionada, contrariando sua própria postura, certa vez dobrou os salários dos funcionários sob o pretexto de que gostaria que pudessem ter acesso aos veículos que eles mesmos produziam. Medo e barganha. Segundo Bauman (2013), o real interesse de Ford era mitigar a rotatividade de funcionários, fazendo com que “[...] o dinheiro gasto em sua preparação e treinamento se passe muitas vezes, por toda a duração da vida útil dos trabalhadores" (p.181). Assim, os seus funcionários, mais do que empregados, permaneciam engessados e dependentes de seus empregos, tendo em vista a dívida contraída.

Contextualizando o exemplo citado, o empregado se sujeita a permanecer na empresa em que seus direitos são reduzidos e em que é expropriado, porque tem compromissos a cumprir, não exatamente com o empregador, mas com sua própria subsistência.

A globalização não respeita limites geográficos; promove a dependência entre os países, principalmente daqueles menos desenvolvidos econômica e socialmente. A perda da autonomia na tomada de decisões nas áreas sociais e econômicas está vinculada aos interesses dos países mais poderosos, que ditam as regras e condutas, em detrimento dos interesses das localidades.

Pela ausência de fronteiras, o mundo globalizado, mesmo dividido em continentes, pode ser agrupado facilmente em uma tela de computador ou smartfone, 
através da rede mundial de computadores. As tendências e decisões adotadas em qualquer lugar do planeta alcançam o exato extremo em questões de segundos, incorporando-se e tomando feições peculiares e próprias do local para onde foram exportadas, a ponto de não ser possível mais distinguir se nasceram ali ou se foram, de fato, inseridas. Romper com os limites geográficos e seguir padrões mundiais é a lei incontrolável da globalização.

Ressalta-se que, conforme explica Bauman,

[...] o significado mais profundo transmitido pela ideia da globalização é o do caráter indeterminado, indisciplinado e de autopropulsão dos assuntos mundiais; a ausência de um centro, de um painel de controle, de uma comissão diretora, de um gabinete administrativo (BAUMAN, 1999, p. 66).

Dessa forma, também faz parte da globalização e da mentalidade daqueles que se alimentam e se beneficiam dela, promover a mentalidade de que devem ser alcançados os padrões mais elevados de consumo e as estratégias de desenvolvimento dos países mais ricos, de forma a se criar uma padronização que fortaleça a hegemonia já estabelecida pelos mais poderosos.

Um exemplo de como a ausência de barreiras gerada pela globalização pode repercutir no âmbito trabalhista brasileiro, vem da França. Uma reforma nas leis ocorrida no primeiro semestre de 2016 encampada pelo governo francês sem a submissão ao parlamento, concedeu maior flexibilidade às empresas para acordarem junto aos funcionários as jornadas de trabalho, além de apresentar condições menos restritivas às empresas que demitem por razões econômicas. As mesmas condições estão sendo estudadas para serem aplicadas no Brasil, sob o pretexto de modernizar a Consolidação das Leis Trabalhistas e de estancar a crise econômica, evitar demissões e conter os índices de desemprego (MATOSO, 2016). 
Assim, tramitam no Congresso Nacional brasileiro, projetos de lei como, dentre tantos outros, a PL 4962/2016 ${ }^{6}$, de autoria do deputado federal Júlio Lopes, do Partido Progressista (PP) do estado do Paraná. Em sua justificativa, o autor usa, entre outros argumentos, a validade e viabilidade da submissão da vontade das partes envolvidas na relação laboral às convenções e aos acordos coletivos.

O que os dispositivos constitucionais que tratam expressamente sobre negociação coletiva, sob o prisma de seus instrumentos normativos, que são as convenções e acordos coletivos, estabelecem é que as convenções e acordos coletivos de trabalho são fontes formais e materiais de estabelecimentos de direitos trabalhistas e que, no caso de salário e jornada de trabalho, é possível sua redução, mediante tutela sindical. É o que está expresso na Constituição.

Ou seja, normas legais que disponham sobre verbas salariais e jornada de trabalho são passíveis de flexibilização, desde que esta se faça através de negociação coletiva entre empresas e sindicatos, nos limites da Constituição.

Assim, ainda que encontre limites constitucionais, a jornada do trabalhador brasileiro também poderá sofrer alterações que em nada trarão de benefício para o mesmo. Um exemplo são convenções coletivas, ou seja, acertos feitos entre sindicatos patronais e de trabalhadores, que estabelecem o pagamento de 20 (vinte) minutos de jornada in itinere, quando na verdade, o tempo demandado da residência do trabalhador até o local de trabalho e vice versa, é pelo menos três vezes mais. O tempo real não seria remunerado, mas apenas aquele convencionado entre as partes. Assim, o artigo 58 da Consolidação das Leis Trabalhistas em seu $\S 2^{\circ}$, determina que,

[...] o tempo despendido pelo empregado até o local de trabalho e para o seu retorno, por qualquer meio de transporte, não será computado na jornada de trabalho, salvo quando, tratando-se de local de difícil acesso ou não servido por transporte público, o empregador fornecer a condução. (BR.ASIL, 2007)

\footnotetext{
${ }^{6}$ http://www.camara.gov.br/proposicoesWeb/fichadetramitacao?idProposicao=2081782 acesso em 06 de setembro de 2016.
} 
Assim, a jornada in itinere deve ser considerada hora extra, devendo os mesmos ser considerados nulos a teor do artigo $9^{\circ}$ do diploma laboral, que determina que "[...] serão nulos de pleno direito os atos praticados com o objetivo de desvirtuar, impedir ou fraudar a aplicação dos preceitos contidos" na CLT.

Dessa forma, os referidos acordos coletivos contrariam o que determina o $\S 2^{\circ}$ do artigo 58 do texto consolidado, vez que não pode nem deve um acordo coletivo impor aos trabalhadores renúncia de direitos adquiridos ou aqueles que emanam de texto legal, de forma que simplesmente desobrigue a empresa reclamada de remunerar corretamente as horas in itinere. Por outro lado, sendo um acordo entre as partes da relação trabalhista e apesar do princípio da autodeterminação dos ajustes de ordem coletiva, o convencionado deve sempre observar o patamar mínimo civilizatório, o que impede renúncia de direitos, especialmente quanto a jornada laboral. Porém, em caso de se transformar lei o já mencionado projeto, esses mecanismos de proteção dos direitos trabalhistas restariam frustrados.

$\mathrm{O}$ autor do referido projeto de lei também utiliza do argumento de que a flexibilização dos direitos trabalhistas é uma tendência global, utilizando-se de um precedente do Supremo Tribunal Federal.

A exegese desses dispositivos constitucionais relativos à negociação coletiva foi realizada pelo Supremo Tribunal Federal, no precedente RE 590.415-SC (Rel. Min. Luís Roberto Barroso, julgado em $30 / 04 / 15$, por unanimidade), ao exercer o controle de constitucionalidade das decisões judiciais da Justiça do Trabalho, vindo a traçar limites menos restritivos à autonomia negocial coletiva, assim se pronunciando:

DIREITO DO TRABALHO. ACORDO COLETIVO. PLANO DE DISPENSA INCENTIVADA. VALIDADE E EFEITOS. [...] 3. No âmbito do direito coletivo do trabalho não se verifica a mesma situação de assimetria de poder presente nas relações individuais de trabalho. Como consequência, a autonomia coletiva da vontade não se encontra sujeita aos mesmos limites que a autonomia individual. 4. A Constituição de 1988 , em seu artigo $7^{\circ}$, XXVI, prestigiou a autonomia coletiva da vontade e a autocomposição dos conflitos trabalhistas, 
acompanhando a tendência mundial ao crescente reconhecimento dos mecanismos de negociação coletiva, retratada na Convenção n. 98/1949 e na Convenção n. 154/1981 da Organização Internacional do Trabalho. O reconhecimento dos acordos e convenções coletivas permite que os trabalhadores contribuam para a formulação das normas que regerão a sua própria vida [...].

Caso seja aprovado o referido projeto de Lei, será alterado o art. 618, da CLT, que deverá apresentar a seguinte redação:

\begin{abstract}
Art. 618 - As condições de trabalho ajustadas mediante convenção ou acordo coletivo de trabalho prevalecem sobre o disposto em lei, desde que não contrariem a Constituição Federal e as normas de medicina e segurança do trabalho.

$\S 1^{\circ}$ - No caso de flexibilização de norma legal relativa a salário e jornada de trabalho, autorizada pelos incisos VI, XIII e XIV do art. $7^{\circ}$ da Constituição Federal, a convenção e acordo coletivo de trabalho firmado deverá explicitar a vantagem compensatória concedida em relação a cada cláusula redutora de direito legalmente assegurado.

$\S 2^{\circ}$ - A flexibilização de que cogita o parágrafo anterior limita-se à redução temporária de direito legalmente assegurado, especialmente em período de dificuldade econômica e financeira pelo qual passe o setor ou a empresa, não sendo admitida a supressão do direito previsto em norma legal.

$\S 3^{\circ}$ - Não são passíveis de alteração por convenção ou acordo coletivo de trabalho normas processuais ou que disponham sobre direito de terceiro.

$\S 4^{\circ}-$ Em caso de procedência de ação anulatória de cláusula de acordo ou convenção coletiva que tenha disposto sobre normas de medicina e segurança do trabalho, processuais ou de direito de terceiros, deverá ser anulada igualmente a cláusula da vantagem compensatória, com devolução do indébito.
\end{abstract}

Dessa forma, passaria a prevalecer aquilo que foi negociado entre as partes, em detrimento do que, historicamente, foi legislado. $\mathrm{O}$ risco ao trabalhador reside no fato de que, em um cenário de acentuada crise econômica e com um evidente e precário modelo sindical, tal lei se prestaria apenas para a retirada de direitos e para a precarização das condições de trabalho, sem qualquer ganho ao trabalhador. 


\section{Supressão do Direito ao Lazer, como um dos Efeitos da Globalização}

Como observado, a globalização tem o poder de transformar qualquer coisa, conceito, direito, parâmetro que pareça sólido, inclusive as leis trabalhistas. Assim, a flexibilização dos direitos trabalhistas é um produto da globalização, encomendado pelas potências mundiais. A globalização, que relativiza direitos trabalhistas, contribui para que aqueles obreiros que ainda estão empregados permaneçam nessa condição, com direitos flexionados, não porque assim o desejam, mas por que veem no salário, o bote salva-vidas que evita o afogamento em meio às ondas gigantescas da crise econômica.

É o medo de perder até mesmo o pouco; é a aceitação das condições da barganha que os fazem conservar o status quo. Para permanecer com o vínculo empregatício, o trabalhador deve, além de desenvolver seu oficio, administrar uma relação de perdas e incertezas.

\footnotetext{
"Flexibilização" é o slogan do dia, e quando aplicado ao mercado de trabalho augura um fim do "emprego como conhecemos", anunciando em seu lugar o advento do trabalho por contratos de curto prazo, ou sem contratos, posições sem cobertura previdenciária, mas com cláusulas "até nova ordem". A vida de trabalho está saturada de incertezas (BAUMAN, 2013, p. 185).
}

A flexibilização dos direitos, ressalta-se, não se trata de medida que visa assegurar postos de trabalho. É, antes de tudo, um conjunto de medidas aceitáveis que se prestam a contornar a crise. Também é o reflexo da necessidade de manter as portas das empresas abertas, com linhas de produção em funcionamento, para que os donos do capital possam ser capazes de prosseguir comprando mão-de-obra, ainda que de forma barateada. Por outro lado, gera uma estabilidade relativa, tanto para o empregador, que permanece com sua atividade econômica, quanto para o empregado, que permanece com seu posto de trabalho. 
Tais elementos da globalização, conforme explica Bauman (2013, p.208, tem a capacidade de neutralizar no indivíduo a "autoconfiança no presente", onde tudo passa a ser transitório e extremamente fluído. Assim, no trabalhador já não há mais a convicção de progresso, o medo gerou incerteza e o pouco assegurado passar a fazer enorme sentido.

Frente a crise econômica de dimensões mundiais, na maior parte das vezes construída artificialmente, o Direito do Trabalho é o primeiro a ser provocado a flexibilizar-se. Ou seja, nem mesmo os direitos trabalhistas, inseridos no rol dos direitos fundamentais, parece ter força para opor-se à onde destrutiva da globalização.

Acompanhando os ventos do constitucionalismo social do início do século $\mathrm{XX}$, o direito do trabalho, como princípio fundamental, é inserido na Constituição Federal de 1937. A partir deste importante marco, várias leis foram promulgadas a fim de assegurar direitos aos trabalhadores. Assim, em 1943, houve a Consolidação das Leis do Trabalho, pelo Decreto-Lei 5.452 de $1^{\circ}$ de maio de 1943, a CLT. Em seguida, várias inovações ocorreram no sentido de fortalecer ainda mais as relações trabalhistas, inclusive com alguns constando na Constituição Federal de 1946, mas foi com a promulgação da Carta Magna em 1988, com o apogeu do processo de democratização do país, que houve a ampliação considerável dos direitos sociais, particularmente, dos direitos trabalhistas.

Há de se observar que a Carta de 1988 é considerada como um marco jurídico de transição democrática e da institucionalização dos direitos humanos no país (PIOVESAN, 2015), fruto de um extenso processo de democratização, iniciado após vinte e um anos de ditadura militar que perdurou de 1964 a 1985. 
Nota-se, portanto, que o direito ao trabalho e seus desdobramentos são assegurados na Declaração dos Direitos Humanos de 1948 e, mais tarde, vieram a refletir diretamente na estruturação da Consolidação das Leis do Trabalho brasileira (BARROS,2008).

No âmbito trabalhista brasileiro, a previsão constitucional é o sinal da evolução dos direitos humanos de um modo geral e do reconhecimento da importância deste direito para a vida do ser humano e para o próprio trabalhador.

Ainda, há no art. $60, \S 4^{\circ}$. Inc. IV, CF, elementos que não podem ser objeto de deliberação. Ou seja, não deveria ser jamais permitido que as propostas de emenda constitucional, causassem a abolição das garantias individuais.

Por fim, é preciso observar o conflito existente entre os projetos de lei que pretendem a flexibilização dos direitos trabalhistas e outros dispositivos da Constituição Federal de 88, como o princípio da dignidade da pessoa humana (Art. $1^{\circ}$, inciso III), os valores sociais do trabalho (Art. ${ }^{\circ}$, inciso IV), da valorização do trabalho humano (Art. 170, caput), o primado do trabalho, no bem estar e na justiça sociais, ambos disposto no Art. 193. Ou seja, para além de toda a renúncia e flexibilização de direitos trabalhistas, carregam consigo o caráter de inconstitucionalidade.

Dentre as propostas de flexibilização dos direitos trabalhistas, um que é confrontado no cotidiano do trabalhador, é o direito ao lazer, que representa o caráter holístico do indivíduo, direito que se insere no rol dos direitos humanos, do direito à dignidade.

O lazer pode ser um conjunto de ocupações às quais o indivíduo consegue entregar-se de livre vontade, seja para repousar, seja para divertir-se, recrear-se e entreter-se ou, ainda, para desenvolver sua informação ou formação desinteressada, sua 
participação social voluntária ou sua livre capacidade criadora após livrar-se ou desembaraçar-se das obrigações profissionais, familiares e sociais (DUMAZEDIER, 2004). Por outro lado, o trabalho, o exercício de uma função, profissão e/ou ofício é algo salutar não somente para mover uma sociedade com suas necessidades e ofertas e assim fazer girar a grande roda de uma estrutura econômica-social, mas também, sob a ótica do indivíduo, por trazer dignidade ao ser humano, uma vez que torna possível alcançar a paz de espírito, através da promoção do seu próprio sustento e o sustento da sua família e dependentes (OLIVEIRA, 2010).

Porém, a humanidade, ao longo dos séculos, debruçou-se a definir o lazer como um direito fundamental ao ser humano, firmando pactos e tratados para que todo ser humano tivesse a liberdade e o direito ao lazer. Assim, percebe-se que ainda que o lazer possa ser considerado superficial e subjetivamente como o "não fazer nada", ainda assim, está intrinsecamente ligado às condições de trabalho.

A Constituição Federal de 1988 institucionalizou um regime politico democrático no país, e inegavelmente, foi responsável por colocar novamente o Brasil no cenário internacional, ao lado de nações que também resguardam e promovem a defesa e garantias fundamentais ao ser humano. Assim, a constituição Federal de 1988 se relaciona com todo o arcabouço internacional de proteção aos direitos humanos, considerando cada um deles como uma unidade indivisível, interdependentes e interrelacionados.

Nesta sistemática, observa-se que a Constituição Federal adotou uma divisão onde o termo "direitos fundamentais" é gênero dividido em espécies, quais seja, direitos individuais, coletivos, sociais, nacionais e políticos. Assim, observa-se que as Constituições escritas estão vinculadas às declarações de diretos fundamentais. Aliás, a 
própria Declaração dos Direitos Humanos de 1948 cita como um dos motivos determinantes da Carta, o comprometimento dos povos em zelar pelos direitos, garantias e liberdades fundamentais.

Nota-se, portanto, que o direito ao trabalho e seus desdobramentos, como o direito ao lazer, são assegurados na Declaração dos Direitos Humanos e, mais, vieram a refletir diretamente na estruturação da Consolidação das Leis do Trabalho brasileira (BARROS, 2008).

Assim, a CLT, em seu artigo 24, faz a previsão expressa de que o trabalho e aspectos inerentes, devem ser objeto de atenção e proteção, bem como o direito ao lazer, uma vez que preconiza que é direito de toda pessoa o repouso, o lazer, a limitação razoável da jornada de trabalho e inclusive de férias periódicas remuneradas.

No âmbito trabalhista brasileiro, a previsão constitucional é o sinal inequívoco da evolução dos direitos humanos de um modo geral e do reconhecimento da importância deste direito para a vida do ser humano e para o próprio trabalhador. Porém, deve ser observado que os efeitos da globalização, como a relativização e a flexibilização de direitos, podem afetar não somente a relação laboral, como, por exemplo, a ampliação da jornada de trabalho, através de pactuações coletivas entre sindicatos, como o próprio direito ao lazer, expresso no artigo $6^{\circ}$ da CLT.

O direito ao lazer, assim como os outros direitos relacionados no mesmo artigo, são indispensáveis para atender às várias necessidades básicas do ser humano. Nascimento (2011) ressalta que, no direito ao lazer, são sanadas necessidades como de libertação, contrapondo-se à angustia e ao peso que são experimentados na angústia que acompanham a vida do trabalhador, principalmente em atividades não escolhidas livremente. Para tanto, os trabalhadores precisam do tempo livre para decidir como 
usufruir tal direito. Evidente que a flexibilização dos direitos trabalhistas afetam muitos direitos, mas é essencialmente o direito ao lazer o primeiro a ser suprimido, retirando do trabalhador o direito de participar da vida ativa em sociedade, em família e/ou para si próprio, decidindo livremente como utilizá-lo. Certamente a supressão do direito ao lazer pode ser considerada um dano colateral da globalização à vida moderna, líquida, fragmentada, como destacado por Bauman.

\section{Conclusões}

Do exposto surgem algumas conclusões pertinentes ao estudo, e que podem assim serem apresentadas.

A globalização criou um novo status ao cidadão: o de consumidor. De trabalhador, cidadão participativo, o modelo imposto cria o consumidor. Todo o tempo é destinado aa serviço incondicional das relações laborais, sem a clara distinção se se consome para viver ou se vive para consumir. É a reificação do humano.

A globalização a que está submetida a sociedade mundial criou formas novas de realização do trabalho, fluidas, vinculadas não mais ao local, mas transnacionais, que impõem angústia e sofrimento ao trabalhador, reduzindo sua dignidade pela adesão simples ao emprego como forma de poder participar da sociedade de consumo. Nesse sentido, os postos de trabalho são abertos e fechados não por decisões locais, mas por interesses transnacionais, que visualizam o lucro e a mão-de-obra barata para a produção de coisas.

Apesar de incluído no rol dos direitos fundamentais, autenticado pelo Estado para propiciar uma vida mais digna ao indivíduo, estando, inclusive, inserido no rol dos direitos fundamentais, o direito do trabalho sofre ataques diretos - tanto por forças 
internas quanto externas - visando a flexibilização, o exercício da atividade laboral sem limites, sem parâmetros de respeito à dignidade da pessoa humana.

O que o mercado quer e forma é o consumidor, cujo trabalho lhe é suficiente para participar desta sociedade de consumo. Na contra mão dessa natureza de fundamentabilidade, estão os efeitos da globalização oferecendo risco e iminente perigo, uma vez que se prestam a alterar, ainda que de forma sorrateira e camuflada os direitos fundamentais.

O direito ao lazer, constitucionalmente previsto, frente à atual crise do mercado, é mais um dos direitos a ser suprimido, tornando, com a flexibilização das horas de trabalho diárias, o trabalhador em autômato que, no conjunto de ações ideológicas de manipulação, dobra seus joelhos e agradece por, neste modelo capitalista de expropriação, ainda ser titular de um emprego que lhe permite participar da sociedade de consumo.

O princípio da dignidade humana expresso na Constituição Federal de 1988, cuja realização se dá por uma vida digna, isto é, por participar ativamente da sociedade, resta mutilado frente ao processo de globalização que impõe, aos países periféricos, seus modelos de desenvolvimento. Retornando a Habermas, a injustiça social é paga com “[...] a moeda forte da existência humana". Certamente que o Direito do Trabalho é mais do que se propõe na economia de uma sociedade globalizada. É o respeito à pessoa humana, sua realização pessoal, social e familiar. É no trabalho e pelo trabalho que o homem se realiza, não como consumidor, mas como ser humano, sujeito livre, capaz de decidir. Neste sentido, a globalização é limite. Se por um lado permite a informação instantânea, por outro, restringe direitos. Pertinente, nesse sentido, a posição de Rawls (2016) sobre instituições justas. Avançar é preciso, mas mais que tudo, avançar com o 
respeito à dignidade da pessoa humana, com o respeito ao trabalho que o dignifica, e, principalmente, com o respeito ao lazer, direito constitucional assegurado como direito fundamental social.

\section{REFERÊNCIAS}

BARROS, Alice Monteiro de. Curso de Direito do Trabalho. 4. ed. São Paulo: LTr, 2008

BAUMAN, Zygmunt. Globalização: As consequências humanas. Rio de Janeiro: Jorge Zahar Editor, 1999.

. Modernidade líquida. Rio de Janeiro: Jorge Zhar Editor, 2013.

. Daños colaterales. Desigualdades sociales en la era global. Buenos Aires: Fondo de Cultura Económica, 2011.

BRASIL. Consolidação das Leis do Trabalho (CLT). 34. ed. São Paulo: Saraiva, 2007.

DUMAZEDIER, Joffre. Lazer e cultura popular. São Paulo: Perspectiva, 2004.

FERRAJOLI, Luigi. Razões jurídicas do pacifismo. Prefácio de Gerardo Pisarello. Tradução de Gustavo de Souza Preussler. Revisão de Alexandre Salim. 2011. No prelo.

FLEURY, Ronaldo. Procurador critica reforma trabalhista: 'apresenta ameaças ao trabalhador'. Disponível em: $<$ https://g1.globo.com/to/tocantins/noticia/2016/09/procurador-critica-reformatrabalhista-apresenta-ameacas-ao-trabalhador.html> . Acesso em: 17 set. 2016.

GUIMARÃES, Samuel Pinheiro. Desafios e dilemas dos grandes países periféricos: Brasil e Índia. Rev. bras. polít. int. v.41, n.1, 1998.

HABERMAS, Jürgen. Um ensaio sobre a Constituição da Europa. Lisboa: Edições 70, 2012.

MATOSO, Filipe. G1 de 24.08.2016. Temer defende reforma trabalhista e diz que é saída para manter empregos. Presidente em exercício deu declaração em evento no Palácio do Planalto. Ele também reafirmou que 'nada é mais indigno do que o desempregado'.Globo.com. Disponível em: $<$ https://g1.globo.com/politica/noticia/2016/08/temer-defende-reforma-trabalhista-e-dizque-e-saida-para-manter-empregos.html>. Acesso em: 09 set. 2016.

MATTEI, Ugo; NADER, Laura. Pilhagem: quando o estado de direito é ilegal. Tradução Jeferson Luiz Camargo. São Paulo WMF Martins Fontes, 2013. 
NASCIMENTO, Amauri Mascaro. Curso de direito do trabalho: história e teoria geral do direito do trabalho: relações individuais e coletivas do trabalho. São Paulo: Saraiva, 2011.

OLIVEIRA, Márcio Batista de. O direito ao lazer na formação do homem social. Âmbito Jurídico. Rio Grande, 13, n. 76, maio 2010. http://ambitojuridico.com.br/site/index.php?n_link=revista_artigos_leitura\&artigo_id=1 4860\&revista_caderno $=25$

PIOVESAN, Flávia. Diretos Humanos e o direito constitucional internacional. 15. ed. São Paulo: Saraiva, 2015.

RAWLS, John. Uma teoria da Justiça. São Paulo: Martins Fontes, 2016.

\section{Endereço dos Autores:}

Daniela Menin

Rua Monte Alegre, 2060, apto 102 Edificio Porto Seguro

Dourados - MS - 79.825-040

Endereço Eletrônico: danameninadv@gmail.com

Helder Baruffi

Rua 143. N. 111. Apto 402

Itapema - SC - 88.200-000

Endereço Eletrônico: helderbaruffi@gmail.com 